\title{
Emergent digital services in public libraries: a domain study
}

\author{
David McMenemy \\ Computer and Information Sciences \\ University of Strathclyde \\ Glasgow
}

Abstract:

Purpose: This paper explores the emergence of digital services in the public library domain via an extensive study of the websites of all Scottish public library services

Design/methodology/approach: In a 4 month period all 32 of Scotland's public library authority websites were visited by a researcher. The goal of the researcher was to record the options available from the library homepages in the following way:

•Role of library in providing page content: content provider or access provider?

-Was the page providing a digital service?

-What was the audience for the page? Adult, child, or not specified?

-Description of page content

-Any noted usability issues

Each site was only visited to three levels below that of the initial homepage.

Findings: The study found a good standard of innovation in digital services around LMS functions, offering users the ability to keep in control of their borrowing and reserving. In addition there was a consistent set of electronic reference resources subscribed to by multiple libraries, offering high quality information both within the library and for library members from their home or workplace. Problems were found with regards to guidance on the usage of these resources, as well as confusion and inconsistency in terminology usage across different library services.

Research limitations/implications: The paper examines only Scottish public library sites, thus can only claim to be representative of that country. It also can only represent the sites at the time they were examined.

Practical implications: The paper should be of interest to public and other librarians interested in patterns across web sites in their sector.

Originality/value: This is the first national study of Scottish public library websites and its findings should be of value as a result.

Keywords: public libraries; digital services; evaluation websites

Article Classification: Research paper

Acknowledgements: The author would like to thank colleague Dr Steven Buchanan for his help in developing the methodology and critique of paper drafts.

\section{Introduction}


This paper explores the emergence of digital services in the public library domain. In doing so it utilises empirical research into the Scottish public library sector, with an extensive study of the websites of the entire Scottish public library network, and the range of services delivered by them.

In a recent review of Scottish public library websites to investigate domain presence and quality of information resources provided it was found that only $9 \%$ of the 32 Scottish public libraries had their own web domains, and it was argued that those without their own domain suffered from a 'virtual identity problem', with several being no more than directory listings within larger local authority sites (McMenemy, 2007). The research also found general inconsistency in library services offered across the sector, with several confusingly (and loosely) co-located with other local authority services. Not surprisingly usability issues were identified, particularly with regard to navigation and terminology, with the paper calling for significant research into the best ways of providing information services to users, and in particular, public library digital services.

This problem is neither new, nor exclusive to Scottish public libraries, as Harden reporting on an earlier UK wide review found that 'many public library websites are little more than digitised leaflets', and argued that such public libraries lacked ambition in the digital age (Harden \& Harden, 1998). Further, a recent review of local council websites by the Society of IT Managers which included public library websites, found that while overall visitor numbers to council websites increased by around $22 \%$ in 2009 , user satisfaction numbers dropped by $18 \%$ (Socitm, 2010). Atherton previously highlighted a proliferation of public sector electronic information islands (Atherton, 2002), and argued that a "key concern facing library and information professionals and local authorities is how to make information available to the citizen without confusion, duplication of effort and in a user-friendly way" (p.467). Even more recently a nationwide survey of public library services indicated that $98 \%$ of services do not have a digital strategy in place (Reading Agency, 2011).

A significant challenge exists in that there is currently limited guidance regarding exactly what public library digital services should be, which is compounded by the nascent state of digital service design and limited previous evaluations of library Internet services (Aitta, Kaleva, \& Kortelainen, 2007; Williams, Chatterjee, \& Rossi, 2008). This paper, then, seeks to contribute to the gap in digital library research related to public libraries. In doing so it also by such a focus considers aspects of the role of the public library in the modern era.

The research questions posed by this paper are:

- What emergent digital services are evident in the sample public library services?

- How is the balance between access provider and content provider being reflected in the range of digital services? 
- What challenges are resulting from the delivery of digital services?

\section{Context of research}

The research and authorship of this paper was undertaken in a period when the recession that has impacted on many western countries, including the United Kingdom, was leading to massive cuts in public expenditure, with a knock-on impact on the delivery of public library services. Estimates have been made that up to $20 \%$ of public libraries will close in the UK in 20011/12 fiscal year alone, with this being only the first year of the proposed cuts. With the reduction in the physical infrastructure, the webpages of public libraries take on an increasing importance in delivering services to users. Thus enhancing and expanding the availability of digital services that library users can access outside of the physical library building is likely to become even more important for library managers.

Koehn and Hawamdeh argue there are cultural issues at play also as the "increasing quantity of born-digital material and the growing preference of users for digital information access are forcing libraries to rethink their strategy in managing financial resources and serving the greater community" (p.162). Research conducted by D'Elia et al involving telephone interviews with just under 4000 members of the public concluded that, "the Internet was overwhelmingly preferred over the library for the majority of uses, many of which fall under the library's traditional mission of information provision" (p.818). The growth in public ownership of enabling technologies has been exponential, and the modern smartphone is capable of accessing the WWW, displaying e-books and digital audio and video, which leads the author to reflect on the observation of $D^{\prime}$ Elia et al that, "people who are using both the library and the Internet can now compare the performance of both providers, and are likely to make choices between the two based upon these comparisons" (p.803). In their study D'Elia et al posed three scenarios for the impact of the Internet on public libraries.

1. Status Quo - where the public library and Internet will co-exist providing complementary services

2. Change - where the public library has to adapt to a new mission and drop some services in the realisation that the Internet provides some of its traditional core mission

3. Obsolescence - that the public library ceases to exist as a result of the Internet supplanting it (D’Elia, Jorgensen, Woelfel, \& Rodger, 2002).

Much earlier in 1998 in the UK context, Harden \& Harden agreed that public librarians should see their websites as an opportunity to enhance services, and should embrace, "the power of the Internet to provide a new medium for delivering library services in innovative ways to existing and new audiences" (p.8). The question remains whether the public library, even the website provided 
by it, would factor into the minds of potential users as being somewhere to satisfy a query when utilizing the Internet. The findings of $D^{\prime}$ Elia et al suggest public libraries face a huge challenge here.

\section{Public library services}

Public library services are widely defined within the literature - a review of indicative sources on public libraries identifies a number of generic services: lending services (books, films, music, other media); reference services; provision of information and advice; heritage services; digitisation services; genealogy services; online database subscription services; online access to catalogues; ICT skills training and access to equipment; children and young people's services; and reader development and literacy programmes (Brophy, 2007; Chowdhury, Burton, McMenemy, \& Poulter, 2008; Dempsey, 2000; Dewe, 2006; McMenemy, 2009). While this list may not be exhaustive, it is argued that it accounts for the main types of services delivered by public libraries.

The challenge for public libraries in the digital age is a fundamental one; do they indeed have a continuing role in an era of the WWW, e-books, and with the ubiquity of devices available to citizens to access such services? Indeed even beyond the public library, "the question is being asked (Brophy, 2000) as to whether information and library services, in any recognisable form, will be needed in the new millennium" (p.163). As has been observed (Wooden, 2006), "with the advent of computers and search engines, digital libraries, and the Internet, some question if libraries are essential and whether they should command priority" (р.3). That said, it is clear that public library websites have a potentially important role in bringing together information "on topics such as education, health, employment, government, economic development, community and social services" (Liu, Martin, Roehl, Yi and Ward, 2006, p.132).

\subsection{The emergence of digital services in UK public libraries}

In the context of the United Kingdom, the development of public library websites coincided with the focus of central government on delivering electronic government (e-government). As branches of local government, public libraries were subject to the same regulations as other government departments in terms of ensuring their services should be delivered via e-government where possible.

This drive towards e-government was a mainstay of the previous UK government's policy to modernise society; in its white paper Modernising Government (HMSO, 1999) it proposed to create an "information age government" ready to lead in developing the knowledge society. It targeted for $25 \%$ of government services that could be provided digitally to be done so by 2002 , and $100 \%$ by 2008. In doing so it identified a vital role for public libraries in enabling citizens to access to these e- 
government services. Thus the public library was expected to be an information gateway for citizens, but at the same time had an important responsibility in adhering itself to e-government policy in providing digital services of its own.

\subsubsection{Existing taxonomical structures}

As part of the movement towards efficient e-government services in the UK, much work has been undertaken in the area of taxonomical development; indeed such work has often seen the involvement of public librarians. Notably the seamlessUK project was an early example of a public library service aiding in the development of taxonomic structures for local authorities (Atherton, 2002). The later development of the Integrated Public Sector Vocabulary (IPSV), the second edition of which was launched in 2006, saw the different threads of work brought together into one overarching taxonomical structure for government services.

The reality for public libraries is that as administrative units of the local authority, the IPSV clearly offers useful structures for many of the aspects of the information they provide. Its structure related to defining library and information services can be seen below:

Library and information services (5733)

- Archives (580)

- Business information services (5734)

- Call centres (7834)

- Enquiry services (7874)

- Libraries (581)

- Children's libraries (5726)

- Library loans and fines (5737)

- Library stock sales (5740)

- Mobile libraries (5725)

- Public libraries (5724)

- Branch libraries (5729)

- Reference libraries (5731)

- Library services to housebound people (5741)

- News feeds (7858)

- Tourist information services (5713) 
The challenge for public libraries in presenting their digital services is that as organisations they exist to provide the public with access to the range of the world's knowledge, and will inevitably provide services outside of categories defined as government services. If we consider the bookshelves of the public library, they are not limited to organising content related solely to government services.

\subsubsection{The emerging roles and responsibilities of the public library}

In delivering the modern iterations of the service discussed above, there exists a further challenge for the public libraries which must be addressed - the balance of the role of the public library; "designer and host; transaction service provider; and as facilitator through the provision of free ICT facilities" (Warren \& Goulding, 2006). The historic role of the public library has been predominantly as access provider, or intermediary if you will; the library service purchased, organised and stored the collections for the users to access when they needed to. Content creation obviously did occur, mostly related to the construction of library instruction guides and the like, and in some services local history materials such as village or town histories and access guides to genealogical materials.

In the digital age the role of access provider grows in importance as reference materials have increasingly become accessed via the Internet. Purchasing of e-resources is a relatively new consideration for public library managers who previously, unlike colleagues in academic or corporate libraries, had not had to consider the provision of such resources to any great extent. Research into the consortium purchasing of such products suggests consortia in parts of England found the exercise to be expensive, cumbersome, and reactivate to approaches directly from the publishers (Ball, 2003). In Scotland an early model of adoption saw a Scotland-wide consortia deal to provide access to three services, Kompass UK, KnowUK, and Newsbank (Kerr, 2003). This provided digital access to a wealth of reference information such as information on UK companies, general access to a range of standard reference information on UK issues, and subscriptions to electronic back copies of newspapers.

With the provision of such services come challenges, adding new responsibilities for the public library manager, with potentially huge contracts to be negotiated, access to be designed and delivered, and training to be organized for both staff and users. The public libraries must consider the licensing of the resources carefully, with all of the inherent challenges this brings in terms of intellectual property rights and equitable access. As Williams, Chaterjee and Rossi (2008) highlight, the "concept of digital rights is just one area where the provider of a digital service might represent a large number of digital owners in their interactions with other parties" (p.506). Public library managers are faced with issues such as differing licensing contracts across multiple suppliers, as well as convincing suppliers that remote access is secure via passwords issued by the library service. 
Indeed Ball's findings from a survey of English public library consortia (2003) saw the issue of licenses as a "minefield" for public library managers, and questioned whether the skills and experience in the sector was suitable for this new service responsibility.

Purchasing and provision of electronic resources, then, is an important consideration for public libraries from several points of view. As well as the responsibilities related to aggregating access to multiple databases for large numbers of users discussed above, ensuring the resources purchased are suitable for the users the library represents must be a crucial concern. Digital libraries designed primarily for educational or corporate clients may not be as suitable for a service that aims to provide services for all members of the public, many of whom who may have limited or nonexistent experience of interacting with digital libraries, or even information technology at all. As Koehn and Hawamdeh (2010) observe, "some of these resources are specialized and serve only a small segment of public library patrons" (p.162). This raises significant challenges for the public library in terms of accessibility that need to be addressed via training and also extensive market research as to the nature of the digital divide within the communities it represents. It is important for the public library to know, for instance, how much investment they will need to make in providing computers for their users to use to access such databases. In summary, "it will continue to be important for libraries to remain informed, to learn what they can about contracts, licensing, and negotiations, and to figure out how to best serve their patrons with these resources (Koehn and Hawamdeh, 2010, p.173)

\subsubsection{The digitization function}

As well as providing access, digital technologies have also afforded public libraries opportunities to enhance their role as content creators. The unique local collections available in public libraries around the world are clearly of local interest, but may also be of national or even international importance. Provision of local content created by the library service can also work as an efficient marketing tool to encourage library users unsure of embracing technology; creation of digital resources about things local users know about is far more likely to encourage them to utilize the service.

In the UK as part of the People's Network programme, public libraries were encouraged to create digital collections of their own materials to make available via their websites; the idea was this material would be aggregated through a national gateway. The overall aim was, "to create innovative online resources of benefit to every UK citizen, bringing together over 500 partner organisations to create support for lifelong learning under the broad themes of citizenship, reskilling, and cultural enrichment" (Nicholson \& MacGregor, 2003). Funds in the region of $f 50 \mathrm{~m}$ were 
set aside for this programme in the late 1990s, and several public libraries benefitted from the funding to kick start digitization programmes.

The European Union were also keen to promote public library digitization programmes and encourage collaboration and partnership working through its PULMAN (Public Libraries Mobilising Advanced Networks) programme (European Commission, 2003).

\section{Investigation of Scottish public library websites}

Public libraries in Scotland are administered by 32 local councils, all of whom have provision of the service among a myriad of responsibilities such as schools, social work, environmental health, and sanitation services to administer. The councils have a statutory obligation to provide a public library service that is "adequate" for people resident in the geographical area served by the council.

Library websites generally operate under the larger corporate banner of the council website, with relatively few having their own domain names or separate websites. As referenced earlier, in a study related to Scottish public library websites only $9 \%$ were found to have their own domains, all others were under the umbrella of the wider council (McMenemy, 2007).

\subsection{The pilot study}

In January and February of 2010 a pilot study involving only 8 local authority library webpages was undertaken. The primary purpose of this stage was to explore the issue of consistency of terminology, which the researcher felt could be achieved through identification and comparative analysis of options available from the homepages of a representative sample of 8 of the 32 Scottish public libraries: Aberdeen; Aberdeenshire; Dumfries and Galloway; Edinburgh; Glasgow; Highlands; Shetland; and Western Isles. The sample covered a wide-ranging demographic, and a major proportion of the Scottish population.

All options from respective homepages were factually recorded, referenced, and listed as a master list using an Excel spreadsheet. Redundant repeat entries were then removed. To reduce subjective interpretation during this step removal beyond entries that shared exact wording was limited to those differing through minor nuance of language (slightly different wording, but semantically the same). Findings would provide an indication as to total number and range of options provided across the Scottish public library sector, and consistency (or not) of terminology adopted.

The analysis of qualitative data is acknowledged as a complex and difficult task (Denscombe, 2003), which must be approached in a systematic and structured manner; however, qualitative data tends to lack the structured numerical characteristics of quantitative data and as a result, often 
requires conceptualisation and interpretation, with interpretation perhaps the key challenge of this research, as given the previously noted issues, it was anticipated that service terminology would be wide ranging across public library websites.

A major output of the pilot stage was the categorisation, with the options available from the respective websites homepages classified into service categories. Classification can either be derived from the data if approached inductively, or based upon a predefined theoretical framework if approached deductively. This stage adopted a predominately inductive approach (appropriate where there is limited existing research to draw on (Ghauri \& Grønhaug, 2005) with categories emerging from grouped information services identified from individual websites (with categories either subdivided or merged with others as appropriate). This step formed an iterative cycle of indexing and cross-referencing, shaped and driven by emergent themes and relationships, with the resultant service taxonomy presented in a hierarchical subject tree format. A controlled vocabulary would have assisted with categorisation, but none were directly applicable.

\subsection{Application of the categories to full study of 32 sites}

Between March and July 2010 all 32 of Scotland's public library authority websites were visited by a researcher. The goal of the researcher was to record the options available from the library homepages in the following way:

- Role of library in providing page content: content provider or access provider?

- Was the page providing a digital service?

- What was the audience for the page? Adult, child, or not specified?

- Description of page content

- Any noted usability issues

In a paper aimed at defining a taxonomy for digital services Williams, Chaterjee and Rossi (2008) defined digital services as those "which are obtained and/or arranged through a digital transaction...over Internet Protocol" (p.506). The author found this definition to be useful, and for this study considered 3 distinct types of service that could be provided by a public library website:

1. Information on information (e.g. description of or confirmation of the existence of materials held by the physical library)

2. Direct access to digital content on PL website (public library as content provider)

3. Indirect access to external digital content via public library website (public library as access provider).

For the purposes of this study the author considered options 2 and 3 as examples of digital services. 
In addition to the categories above, each option was allocated to a category based on the taxonomy developed in the pilot phase. These categories were:

1. Early Learning

2. Scholarship

3. Genealogy and heritage

4. Enterprise and employment

5. Recreational reading

6. Health and wellbeing

7. Community support

8. Reference enquiry

9. Housekeeping (joining information, library rules, mobile library timetables, etc)

10. Does not fit into listed categories

Each site was only visited to three levels below that of the initial homepage; this was to make the volume of work manageable, but also reflected the view of the researchers that access to services within the sites should necessitate a long process of clicking on links, and that they should be findable quickly.

General observations regarding usability were noted throughout both stages. It was not considered practical to attempt to conduct an extensive evaluation of the usability of individual websites, nor necessarily required given the focus of the research to consider the emergence of digital services. However, it was considered of value to consider general aspects of usability, which might inform subsequent design of any taxonomy whether standard or not.

Usability evaluation can be both formative and summative, and is commonly conducted by inspection and/or test, the former without involvement of the user, the latter typically with. Inspection methods include heuristic evaluation, cognitive walkthrough, and action analysis, while test methods include questionnaire, thinking aloud, and field observation (Holzinger, 2005). Given the goals of the research, inspection via heuristic evaluation was considered appropriate, with key usability attributes drawn from a framework (Buchanan \& Salako, 2009) which specifies: learnability; effectiveness; efficiency; aesthetic appearance; terminology; and navigation. It was acknowledged that without actual task execution (and involvement of users), limited consideration could be given to learnability, effectiveness, and efficiency; however, it was felt that terminology, navigation, and aesthetic appearance could be considered within the practical limitations and constraints of the study. 
The data presented below has anonymised the library services studied, since it is not the intention to embarrass or single out specific services with comments, but rather give a national picture of the situation.

\subsection{Limitations of study}

The research undertaken for this article was obviously limited in several areas. Firstly, it represents a study of one geographical region, and while the author believe Scotland should be representative of other UK public library services, this cannot be definitely proven without an extended study.

Secondly, the study represented a point in time in terms of public library development, therefore since the spring and summer of 2010 some Scottish library websites have changed in terms of the services on offer. The author then does not claim the findings are wholly representative of the websites now, only at the period when the study was undertaken.

\subsection{Data from website study}

Across all of the 32 websites examined, 3258 options in total were identified for the study. There was a wide variance in terms of the number of initial options available on each homepage, ranging from 8 to 132.



Figure 1- Number of options available on homepage

In terms of best practice, it is suggested that more than 10 options on a webpage can overwhelm users (Morville \& Rosenfeld, 2007) and only 2 of the 32 websites fitted this criteria. The average number of options across all 32 sites was 25 . In one extreme case, 132 options were available from the homepage. 


\subsubsection{Content provider or access provider?}

This categorisation related to whether the featured options were links to external sites or services, or to content created by the library itself. In the largest number of cases the webpages concerned were delivering content created by the library service itself (64\%); in just under a third of cases (31\%) the library was providing access to an external resource.

Clearly the majority of the website options are library-created content; however the $31 \%$ indicates the increasing importance of external sources in satisfying the information needs of library users. Types of external resource featured included web links to sites of interest, as well as subscribed reference databases, more of which will be said below.

\subsubsection{Issues in consistency of terminology}

The initial list of 3258 options was further distilled to exclude duplicate options within each local authority page, which resulted in a total of 2887 unique options. A pivot table was created with this data set which presented a count of identical options used by more than one local authority. The top ten results with the number of authorities using each term can be found below:

Table 1 - count of unique options utilised by more than one local authority ( $n=32)$

\begin{tabular}{|l|l|}
\hline Library Catalogue & 14 \\
\hline NewsUK & 13 \\
\hline Family History & 11 \\
\hline Contact Us & 9 \\
\hline Libraries & 9 \\
\hline Reading Groups & 9 \\
\hline KnowUK & 8 \\
\hline SCRAN & 8 \\
\hline Ask Scotland & 7 \\
\hline Bookstart & 7 \\
\hline Credo Reference & 7 \\
\hline Local History & 7 \\
\hline $\begin{array}{l}\text { Oxford Reference } \\
\text { Online }\end{array}$ & 7 \\
\hline Scottish Readers & 7 \\
\hline Archives & 6 \\
\hline
\end{tabular}




\begin{tabular}{|l|l|}
\hline Catalogue & 6 \\
\hline FAQs & 6 \\
\hline Library Services & 6 \\
\hline Local Studies & 6 \\
\hline Mobile Library Service & 6 \\
\hline
\end{tabular}

Clearly while there is agreement across a large number of authorities with regards to option categories, there is no majority for any of the terms used on the sites. Notwithstanding that terms such as Library Catalogue and Catalogue are similar in nature; it would not be unreasonable to expect uniformity in specification of services available from homepages. Similar terms such as Local History and Local Studies may be obvious in meaning to the professionals constructing them, but may not be so to users. This becomes all the more important in terms of categories that may not be immediately obvious as to what they are, such as some of the commercial brand names featured prominently like NewsUK or SCRAN.

\subsubsection{Emerging digital services}

When the issue of whether the library is a content creator or access provider is cross-referenced with whether the service is digital, the following chart results:

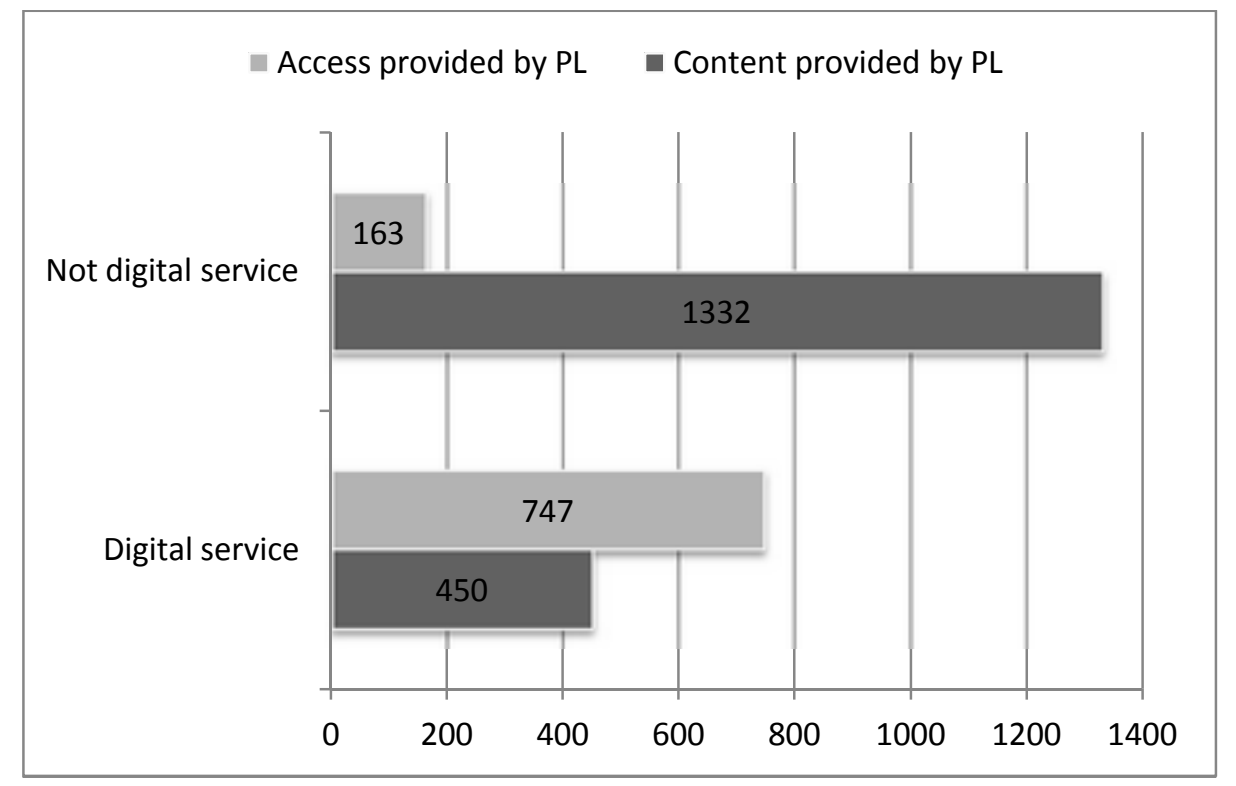

Figure 2 - Content type vs digital service

Libraries were almost 3 times as likely to provide content that is not a digital service, with the digital services provided more likely to be aggregated access to an external source. That said, library services were often consistent in the types of digital service they made available, with all providing 
access to facilities for library users to access their digital borrower records, renew their books online, and the like. Other types of digital services created by the library services included image databases, and community information portals, the emphasis generally being on the local content of specific interest to users from their geographic locale.

Figure 3 presents the data for each individual library service in terms of content and access provision, and while most were similar in terms of the ratio of content vs access, several authorities stood out in terms of being at the extremes of either access or content provision. This varied as to reasons, with some authorities providing much more of their own content via extensive digitisation collections, community information databases, local history provision, or other local content, such as information on local authors.

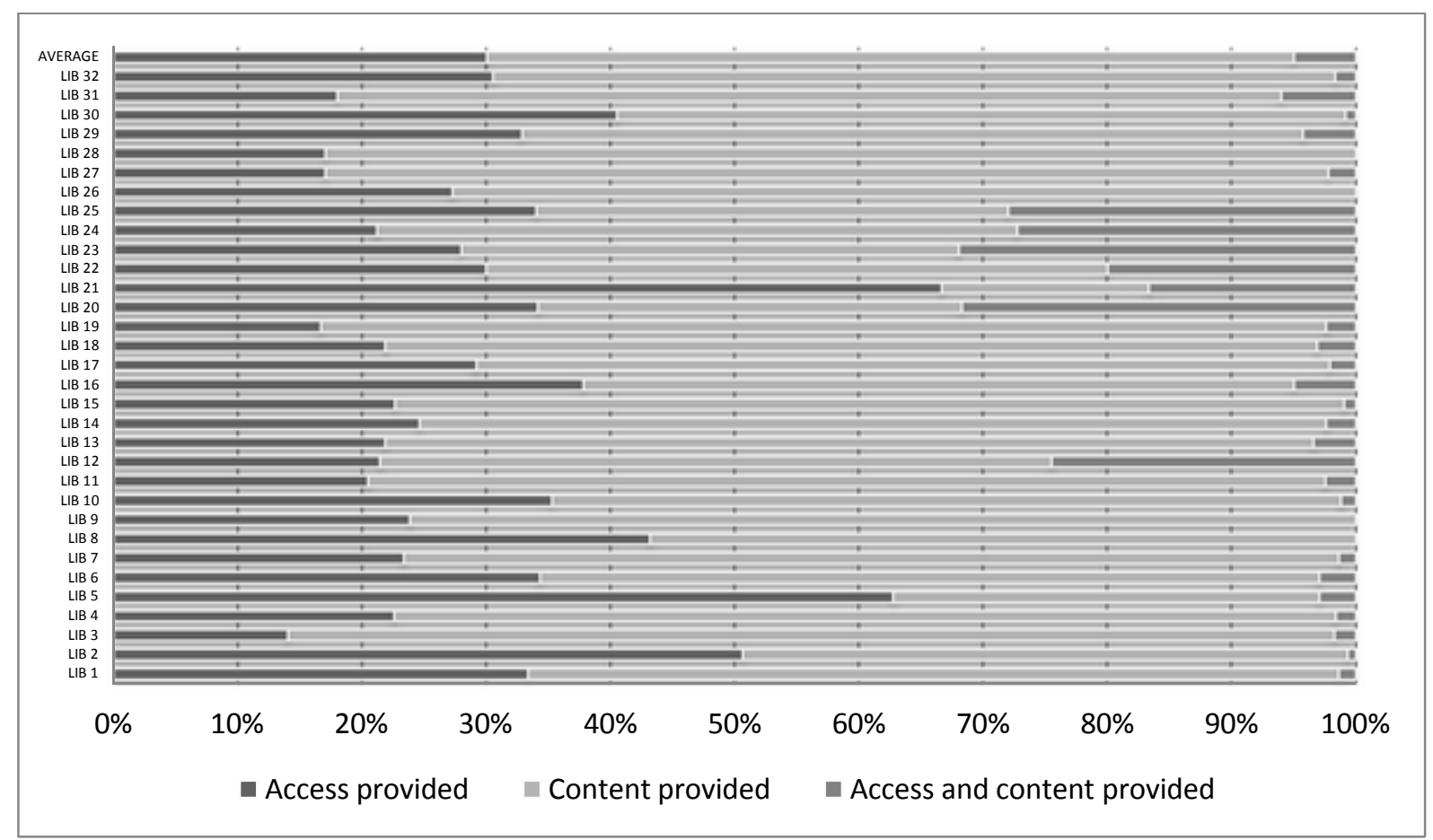

Figure 3 - Authority as access or content provider

Figure 4 presents a breakdown of authorities in terms of their role as digital service provider, and again we see the majority mirroring the average level of provision. However again some authorities bucked this trend by provision of a wider range of digital services such as thise discussed under Figure 3. Clearly when a library service has invested more in its digital offer it can incorporate both local service provision and an emphasis on external databse subscriptions. For those authorities successully offering more digital services this emphasis was clear; a local digitisation strategy 


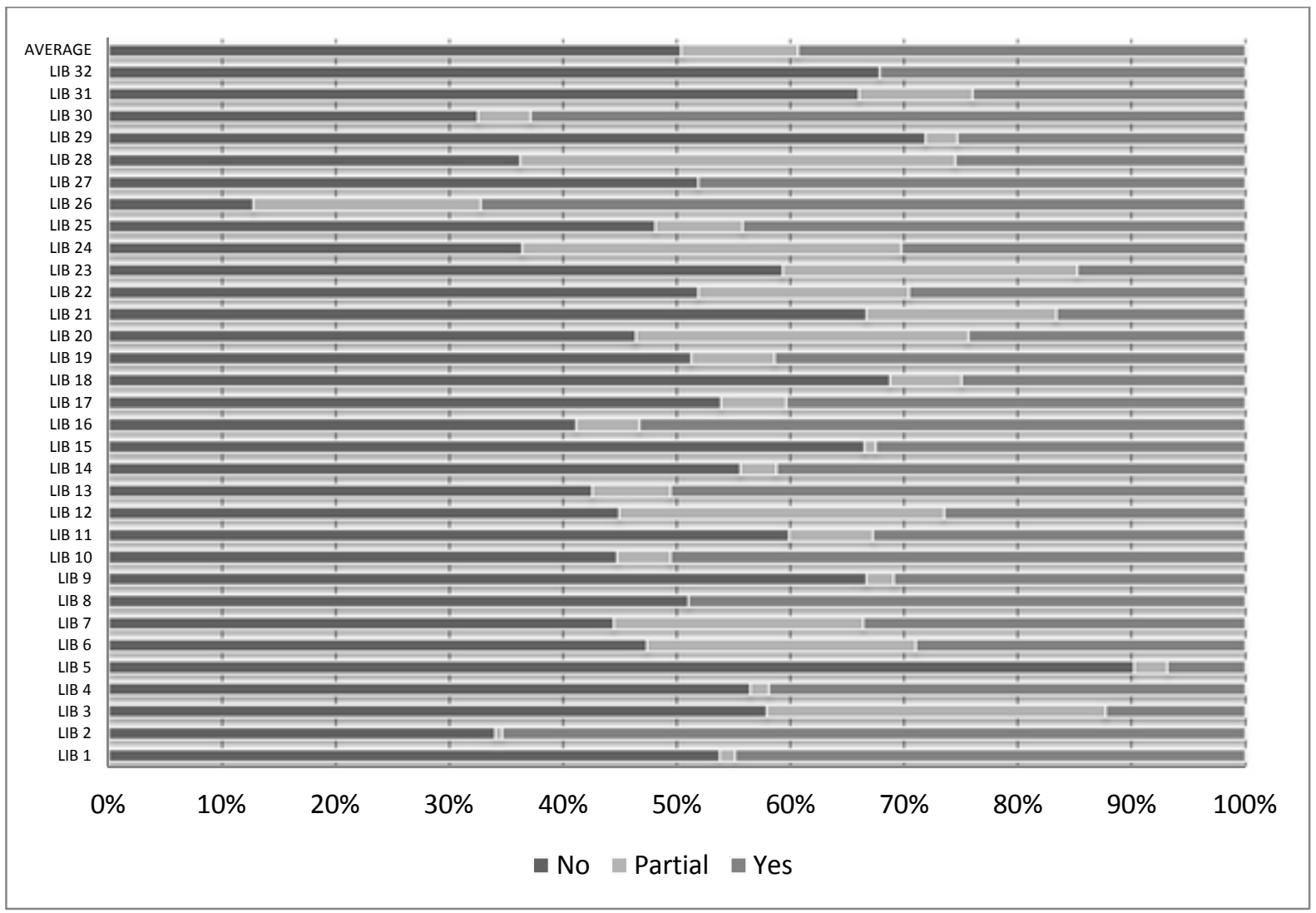

Figure 4 - Authority as digital service provider

The data discussed above included both categories of option, digital services and non-digital services. To determine the characteristics of emergent digital services, further analysis was undertaken whereby only the options categorised as digital services were selected from the main data set. Close analysis was carried out to determine the characteristics of digital services on offer rather than just a list of option titles; to this end, all options of differing title but obvious identical or similar subject/theme (such as catalogue/online catalogue/library catalogue) were all listed under an umbrella term, and a final count of all of these categories was undertaken. This refinement produced 642 options that were classed as digital services.

For space reasons, the 20 most popular digital services are listed below, with the count of how often the option was used across the 32 websites, and the category it comes under:

Table 2 - count of top 20 digital services and how often each was referenced across all 32 sites

\begin{tabular}{|l|l|l|}
\hline OPTION & NO. & CATEGORY \\
\hline Library Catalogue & 52 & Housekeeping (joining, rules, etc) \\
\hline
\end{tabular}




\begin{tabular}{|l|l|l|}
\hline Contact the library service & 23 & Housekeeping (joining, rules, etc) \\
\hline Renew and reserve items & 23 & Housekeeping (joining, rules, etc) \\
\hline NewsUK & 22 & Reference enquiry \\
\hline Britannica Online & 20 & Reference enquiry \\
\hline Mobile Library routes and timetables & 19 & Housekeeping (joining, rules, etc) \\
\hline Ask Scotland & 17 & Reference enquiry \\
\hline $\begin{array}{l}\text { Britannica Junior - homework help for primary age } \\
\text { children }\end{array}$ & 15 & Reference enquiry \\
\hline SCRAN & 14 & Reference enquiry \\
\hline Library ELF & 14 & Housekeeping (joining, rules, etc) \\
\hline KnowUK & 13 & Reference enquiry \\
\hline Oxford Dictionary of National Biography & 13 & Reference enquiry \\
\hline Oxford English Dictionary & 13 & Reference enquiry \\
\hline Library guides & 13 & Housekeeping (joining, rules, etc) \\
\hline Britannica Student & 12 & Reference enquiry \\
\hline Credo Reference & 12 & Reference enquiry \\
\hline Oxford Reference Online & 12 & Reference enquiry \\
\hline Twitter & 11 & Does not fit categories above \\
\hline Clubs and groups & 9 & Community support \\
\hline Theory Test Pro & 9 & Reference enquiry \\
\hline
\end{tabular}

12 the top 20 digital services provided were commercial subscription databases for library members to access either in the library or from home using their library membership credentials. Other notable services related to library management systems functions (LMS) such as reserving or renewing books, or accessing borrower records. Another example of the innovative services provided around the LMS is the Library ELF service, which was utilised by just under a third of the library services under study. This service provides an enhanced service for library members. As well as sending email reminders to members regarding when books are due to be returned, it also offers the ability to be emailed or text messaged when requests have been made. Such a digital service makes using the service more accessible, with less need to visit the physical library or contact it directly to interact with it.

500 of the 642 digital service options were unique, representing such diverse services as interactive sites promoting book titles, or local image databases, or sites constructed by community 
organisations. When this grouping is analysed by subject category, the following results are produced:

Table 3 - count of 500 unique digital services by subject

\begin{tabular}{|l|l|}
\hline Category & No. \\
\hline Does not fit categories & 71 \\
\hline Early learning & 17 \\
\hline Scholarship & 18 \\
\hline Genealogy and heritage & 57 \\
\hline Enterprise and employment & 11 \\
\hline Recreational reading & 102 \\
\hline Health and wellbeing & 22 \\
\hline Community support & 38 \\
\hline Reference enquiry & 28 \\
\hline Housekeeping(joining, rules, etc) & 136 \\
\hline
\end{tabular}

In the recreational reading category some real innovation was evident on the part of some library services, with audio recordings of local authors reading their works included. These were created by the library service to promote local literature, and neatly illustrate how much potential digital services have to promote traditional library services and local culture. Such innovation was also evident in several excellent locally produced digital image collections created by library services under the genealogy and heritage category.

\subsubsection{A suggested initial taxonomical structure}

The subject categories developed in the pilot study, and utilised for the full study, proved effective in categorising many of the services available on the website. However they proved limited in scope, and given the significant number of services that could not be categorised by these options, a more refined taxonomical structure is offered for future categorisation of public library websites. This structure is not claimed to be definitive, merely indicative of the types of services the researchers encountered in their study:

Business resources

Careers and Employment
Company information

Trade directories

Careers information 
$\mathrm{CV}$ and interview help

Job adverts

Children's and Young Peoples services

Author visits

Events

Five to Twelve

Homework support

Pre-school

Teenagers

\section{Community resources}

Family and local history

Government information

Health and wellbeing

Join the library

Learning resources

Library Members

Literature and reading resources
Information for new arrivals Local groups and organisations Schools and nurseries

Travel information

Family history resources Local history resources

Contact your councillor Contact your Member of Parliament Freedom of information Your local council

Bibliotherapy Health charities Local health services NHS services

Download a membership form Join the library online

Adult learning support Course information Courses in the library Homework support Literacy and numeracy Online learning opportunities Resources for students

Access your borrower record Activate your account online Renew your books Reserve a book Sign up for email or text notifications

Author information Book recommendations and reviews Creative writing Literary competitions Local writing Reading groups 
Reference resources

Your library service
Access electronic reference services 24 hours a day

Ask a librarian

Dictionaries

Encyclopaedias

Computing resources

Contact the library

Library charges

Library events

Local libraries

Mobile and housebound library service

Performance information

\section{Discussion}

The data presented from the study of Scotland's public libraries gives much food for thought in terms of the development of digital services in the Scottish public library domain. Several questions are raised, namely:

1. Duplication of provision of digital services

2. Consistency of terminology

3. Assistance and guidance in using external digital services

Each of these issues will be dealt with in turn below.

\subsection{Duplication of provision of public digital services}

The first observation is perhaps potentially controversial; however analysis of the data leads to the question of efficiency in terms of duplication of delivering public information services. This begs the questions as to whether it is desirable for the same type of content relating to the same services to be undertaken 32 times, with the obvious issues that are presented related to the variability of quality inherent in such a scenario.

Certainly the local dimension is of vital importance, and pages need to exist that communicate local information on library services, as well as concentration on local content related to family and community history and the like. However the more generic content and the access provided to external digital services subscribed to by multiple library services could easily be undertaken by a single national body, allowing the local library services to concentrate on prioritizing development of local digital services. The data from this study indicates that public libraries in Scotland are greatly reliant on commercial subscription databases for their digital offer to library members - as such it would seem that collaboration between library services to ensure that members are able to effectively utilise those services would benefit all stakeholders. 


\subsection{Consistency of terminology}

A key concern raised both in the pilot study, and in the extended full study presented in this paper, was the use of ambiguous or confusing terminology, and application of consistent terminology to services. It was not clear on each site, for instance, whether a formal taxonomy had been used to generate the terms used, and indeed given the diversity in defining even simple terms, it would seem that many sites did not in fact use any.

A startling example of this confusion could be found in how the websites categorised materials for electronic reference materials. Each library website had a unique term for this core service, specifically:

\section{Table 4 - terms used on sites to define reference function}

\begin{tabular}{|l|l|}
\hline 24 Hour Enquiry Services & Online Databases \\
\hline 24/7 reference & Online Information Resources \\
\hline Access 24/7 Reference Information from Home & Online Information Service \\
\hline Access information 24/7 & Online reference databases \\
\hline eReference Library & Online reference library \\
\hline Ez-information 24/7 & Online Reference Services \\
\hline Free Information Resources & Online Resources \\
\hline Free Reference Resources & Quick Reference \\
\hline Information and Reference Service & Reference and Information \\
\hline Information Enquiry Service. & Reference Central \\
\hline Information Online & Reference Enquiries \\
\hline Information Services & Reference Library \\
\hline Internet \& Online Subscriptions & Reference Links \\
\hline Libraries - online information resources & Reference Services \\
\hline Libraries - Reference and Information & The 24/7 Library \\
\hline My Library Anytime & YOUR 24 HOUR LIBRARY \\
\hline
\end{tabular}

Clearly when such a core service is being so diversely defined and promoted to users, there is a case for arguing for one consistent approach to presenting digital services to users to be implemented. Again, the author would suggests that collaboration between the 32 public library networks takes place to agree on the usage of a set of descriptors that all can present to users in a uniform fashion. Here pre-existing taxonomic structures such as the IPSV offer a quick solution to an avoidable problem. 


\subsection{Assistance and guidance in using external subscribed digital services}

While the services were consistent in providing access to some extremely useful and high quality external subscription digital services on behalf of their users, they were generally remiss in providing guidance to their users on the nature of these services and how to utilise them. It is notable, for instance, that library guides to collections or some other aspects of the wider service were found in 13 cases during this study. Clearly this is something public libraries have been involved in doing since their inception; however it is plainly easy to leave guidance on using an external product to the company that produces it.

While it could be argued that the library user can access help guides created by the digital services themselves when they log in to them, the nature of the public library user demographic must be taken into consideration here. Provision of such services is for everyone within the community, however to enable equity of access to occur there must be the clearest possible explanation of what the services provide, and how they can be used by the patron. It is not enough just to provide a link to a log-in page; the library must try as much as possible to provide helpful guides in using the resources, just as they would if the library patron was utilizing the service from within the library building. As has been observed, "because information only becomes useful within some sort of context, the interface needs to provide that context or there needs to people readily available to help provide the context" (Lease Morgan, 2000). Not addressing this important issue potentially limits the growth of digital service provision in public libraries. In the context of service management the issue of educating the customer has been highlighted as being crucial in expanding innovation in service delivery (Gummesson, 1994):

We are afraid of educating the customer...In my view it is not only an option but a privilege to educate the customer. It opens up the means for improved services and innovations (p.83).

By not providing appropriate guides to such services, the libraries potentially limit the use of those services by users who may be unfamiliar with the service type. This is regrettable from both equity and fiscal perspectives, but also considering the important historical role of the public library in educating users to make best use of information. The role of the public library as an intermediary is evolving in the digital era; however its responsibility to contextualise such access is as important as ever.

\section{Conclusion}


This paper explored the nature of public library services and their iteration in the digital domain. The focus of the paper was to attempt to discuss emerging digital services provided by Scottish public libraries via their websites.

The study found a good standard of innovation in digital services around LMS functions, offering users the ability to keep in control of their borrowing and reserving. In addition there was a consistent set of electronic reference resources subscribed to by multiple libraries, offering high quality information both within the library and for library members from their home or workplace.

Problems were found with regards to guidance on the usage of these resources, as well as confusion and inconsistency in terminology usage across different library services.

The author would encourage further research into the provision of public library websites by colleagues researching in the field of digital libraries; as has been argued they are now a crucial digital library provider available to all (Liu, Martin, Roehl, Yi, \& Ward, 2006). As such, and given their potential to reach every member of a community, their continued examination in a bid to further understand their reach, relevance, and significance is of vital importance in the development of information services for the general public.

\section{References}

Aitta, M. J., Kaleva, S., \& Kortelainen, T. (2007). Heuristic evaluation applied to library web service. New Library World, 109(1/2), 25-45.

Atherton, L. (2002). seamlessUK - building bridges between information islands. . New Library World, 103(1182/1183), 467-473.

Ball, D. (2003). Public libraries and the consortium purchase of electronic resources. The Electronic Library, 21(4), 301-309.

Brophy, P. (2000). Towards a generic model of information and library services in the information age. Journal of Documentation, 56(2), 161-184.

Brophy, P. (2007). The library in the twenty-first century (2nd ed.). London: Facet.

Buchanan, S., \& Salako, A. (2009). Evaluating the usability and usefulness of a digital library. Library Review, 58(9), 638 - 651.

Chowdhury, G. G., Burton, P. F., McMenemy, D., \& Poulter, A. (2008). Librarianship: an introduction. London: Facet.

D'Elia, G., Jorgensen, C., Woelfel, J., \& Rodger, E. J. (2002). The Impact of the Internet on Public Library Use: An Analysis of the Current Consumer Market for Library and Internet Services. Journal of the American Society for Information Science and Technology, 53(10), 802-820.

Dempsey, L. (2000). 'Scientific, Industrial and Cultural Heritage: a shared approach: a research framework for digital libraries, museums and archives. Ariadne, 22.

Denscombe, M. (2003). The good research guide for small-scale social research projects (2nd ed. ed.). Maidenhead: Open University Press.

Dewe, M. (2006). Planning Public Library Buildings: concepts and issues for the librarian. Aldershot: Ashgate.

European Commission. (2003). The PULMAN Guidelines.

Ghauri, P. N., \& Grønhaug, K. (2005). Research methods in business studies : a practical guide (3rd ed. ed.). Harlow: Financial Times Prentice Hall. 
Gummesson, E. (1994). Service Management: An Evaluation and the Future. International Journal of Service Industry Management, 5(1), 77-96.

Harden, S., \& Harden, R. (1998). Why are we waiting? Observations on how UK public libraries are using the World Wide. VINE, 113, 8-12.

HMSO. (1999). Modernising Government. London: Her Majesty's Stationery Office.

Holzinger, A. (2005). Usability engineering methods of software developers. Communications of the ACM 41(1), 71-74.

Kerr, G. (2003). Value added facts. Information Scotland, 1(1).

Lease Morgan, E. (2000). Personalized Library Interfaces. Exploit Interactive(6).

Liu, Y. Q., Martin, C., Roehl, E., Yi, Z., \& Ward, S. (2006). Digital information access in urban/suburban communities: A survey report of public digital library use by the residents in Connecticut. OCLC Systems \& Services: International digital library perspectives, 22(2), 132-144.

McMenemy, D. (2007). Internet identity and public libraries: communicating service values through web presence. Library Review, 56(8), 653-657.

McMenemy, D. (2009). Rise and demise of neoliberalism: time to reassess the impact on public libraries. Library Review, 58(6), 400-404.

Morville, P., \& Rosenfeld, L. (2007). Information architecture for the World Wide Web (3rd ed. ed.). Beijing ; Farnham: O'Reilly.

Nicholson, D., \& MacGregor, G. (2003). "NOF-Digi": putting UK culture online. OCLC Systems \& Services, 19(3), 97-99.

Reading Agency. (2011). Libraries and Digital: Research into the use of digital media in libraries to develop audiences for reading. London: The Reading Agency.

Socitm. (2010). Better connected 2010: a snapshot of all local authority websites: Socitm.

Warren, A. P., \& Goulding, A. (2006). Public libraries as e-government intermediaries. Paper presented at the Information, Innovation, Responsibility: Information Professional in the Network Society: Proceedings of the 14th BOBCATSSS Symposium, Tallinn, Estonia.

Williams, K., Chatterjee, S., \& Rossi, M. (2008). Design of emerging digital services: a taxonomy. European Journal of Information Systems, 17, 505-517.

Wooden, R. A. (2006). The Future of Public Libraries in an Internet Age. National Civic Review(Winter), 3-7. 